\title{
Possibility of a New Indication for Amantadine in the Treatment of Bipolar Depression-Case Series Study
}

\author{
Marek Krzystanek ${ }^{1, *}$ and Artur Pałasz ${ }^{2}$ \\ 1 Clinic of Psychiatric Rehabilitation, Department of Psychiatry and Psychotherapy, Faculty of Medical Sciences, \\ Medical University of Silesia in Katowice, Ziołowa 45/47, 40-635 Katowice, Poland \\ 2 Department of Histology, Faculty of Medical Sciences, Medical University of Silesia in Katowice, \\ Medyków 18, 40-752 Katowice, Poland; artiassone@gmail.com \\ * Correspondence: m.krzystanek@sum.edu.pl; Tel./Fax: +48-322059260
}

Received: 22 September 2020; Accepted: 20 October 2020; Published: 21 October 2020

check for updates

\begin{abstract}
Bipolar disorder is a chronic and remitting mental illness. Antidepressants are not effective in treating acute bipolar depression, and antipsychotic drugs used in the treatment of bipolar depression cause frequent side effects. This situation justifies the search for new drugs as well as the repurposing of drugs used in other indications. In an open and naturalistic serious case study, 4 patients diagnosed with bipolar I disorder, chronically treated with a mood stabilizer, in whom at least two antidepressants were ineffective in the depressive phase, were treated with amantadine. The woman received $100 \mathrm{mg} /$ day and 3 men received the target dose of $200 \mathrm{mg} /$ day. All patients treated with amantadine improved their depressive symptoms after 1 week of treatment. None of them experienced side effects or manic switch. To reduce the risk of a manic switch, the treatment with amantadine was discontinued 2 weeks after the improvement of depressive symptoms, and no recurrence of depressive symptoms was observed. Amantadine may be a further therapeutic option for the treatment of acute bipolar depression. The drug in this indication may act quickly and be well tolerated. Confirmation of the antidepressant efficacy of amantadine in this indication requires replication of the results and conducting clinical trials.
\end{abstract}

Keywords: amantadine; bipolar depression; bipolar disorder; off-label treatment

\section{Introduction}

Bipolar disorder type I (BD-I) is a disabling and cyclical mental illness whose essence is mood instability, manifested by recurrent episodes of bipolar depression, mania, and mixed states. In addition to these primary symptoms, BD-I causes chronic symptoms in the form of emotional dysregulation, sleep disturbances, cognitive impairment, and subsyndromal mood disturbances between the episodes [1].

BD-I affects about $2 \%$ of the general population; the course of the disease is individual and may differ in severity, duration, and frequency of occurrences [1,2]. Characteristic for BD-I is a longer duration of depressive episodes than of manic episodes. Already Emil Kraepelin described that episodes of depression in bipolar disorder may even persist for years [3]. Contemporary observations indicate an average duration of a depressive episode in $\mathrm{BD}$ of $4-5$ months, i.e., about $50 \%$ longer than the average manic episode [4].

None of the classical mood stabilizers (i.e., lithium, carbamazepine, lamotrigine, and valproate) are well documented for their acute antidepressant effects in bipolar depression [5]. A common practice in the treatment of acute bipolar depression is the use of antidepressants, although they are not effective, and what is more, they increase cycle acceleration, causing a rapid-cycling course, contribute to the formation of mixed episodes and, consequently, reduce the effectiveness of the treatment of bipolar disease $[5,6]$. 
In the treatment of bipolar depression, quetiapine, lurasidone, aripiprazole, cariprazine, and a combination of olanzapine with fluoxetine are usually added to the mood stabilizer [5]. It should be emphasized that the use of quetapine, lurasidone, and olanzapine is a frequent cause of the deterioration of the functioning of patients, caused by the frequent occurrence of metabolic, motoric, and cognitive side effects [6].

Other drugs that may be effective in the treatment of acute bipolar depression include $\mathrm{N}$-acetylcysteine, vitamins $\mathrm{D}_{3}$ or folic acid, hormones tri-iodothyronine or levothyroxine, antibiotic minocycline, anesthetic ketamine, psychostimulant modafinil, and omega-3 fatty acids [6]. All of these adjunctive treatment strategies are off-label indications for bipolar depression, and their efficacy data are mostly derived from single clinical trials, open case series, or case studies.

The limited number of drugs that are effective and well-tolerated in the treatment of a depressive episode in BD indicates the need to seek new drugs as well as repurposing drugs used in other indications. One of the off-label drugs that have an antidepressant effect is amantadine. The molecular mechanism of amantadine's antidepressant action is not yet fully understood as the drug exerts its pharmacological effects through diverse brain signaling systems such as dopaminergic, noradrenergic, glutamatergic, and opioid systems [7]. Several neurochemical scenarios should be considered; however, the effect of amantadine on dopaminergic transmission is relatively well documented.

Amantadine strongly stimulates dopamine signaling by elevation of the neurotransmitter level within the synaptic cleft via the inhibition of the dopamine transporter (DAT). Dopamine reuptake is regulated with phosphorylation of the DAT1 molecule and probably modulated by presynaptic NMDA receptor activity [8]. Amantadine as a weak noncompetitive NMDAR antagonist accelerates its cationic channel closure, blocking ion current and finally inhibiting receptor function [9]. This follows DAT1 blockage and the increase of local dopamine concentration that plays an important role in the origin of the anti-depression effect $[10,11]$. Figure 1 presents the entire spectrum of the mechanisms of action of amantadine, proposed and confirmed in the literature [11-34].

Clinically, amantadine belongs to the group of dopaminergic drugs increasing dopaminergic transmission, which is considered now as an effective add-on treatment of bipolar depression [6]. The rationale for their use in bipolar depression is a dopaminergic model of bipolar depression pathogenesis, which assumes dysfunction in the brain dopaminergic system of patients with BD [35,36]. Dopaminergic drugs, unlike antidepressants, do not seem to increase the risk of manic switch and are well tolerated by patients [6].

To date, most of the clinical data support the efficacy of amantadine in the treatment of recurrent depression. It was first demonstrated by Vale et al. [37] in a group of 20 depressed subjects treated with amantadine at a dose of 100-200 mg/day, but these results could not be repeated in a study published 2 years later by Rizzo et al. [38]. In the following decades, one clinical trial and several series of cases managed to demonstrate the effectiveness of amantadine in the augmentation of treatment-resistant depression [39,40]. Amantadine was also used in patients with the Borna Disease Virus (BDV), manifesting symptoms of bipolar disorder. In this study, they reported a faster improvement in depressive symptoms compared to patients with major depression symptoms [41]. There are no reports regarding the use of amantadine in the treatment of bipolar depression.

\section{Results}

The addition of amantadine to the mood stabilizer resulted in a significant improvement in depressive symptoms in all 4 patients. In 3 men, the dose of amantadine was increased to $200 \mathrm{mg}$ in the morning due to the lack of improvement in the first week. One week after increasing the dose, the severity of depression in these patients was reduced by $44-57 \%$ compared with baseline. In a female patient, after a week of treatment with a dose of $100 \mathrm{mg} / \mathrm{day}$, an improvement of over $66 \%$ was observed. Details are presented in Table 1. 

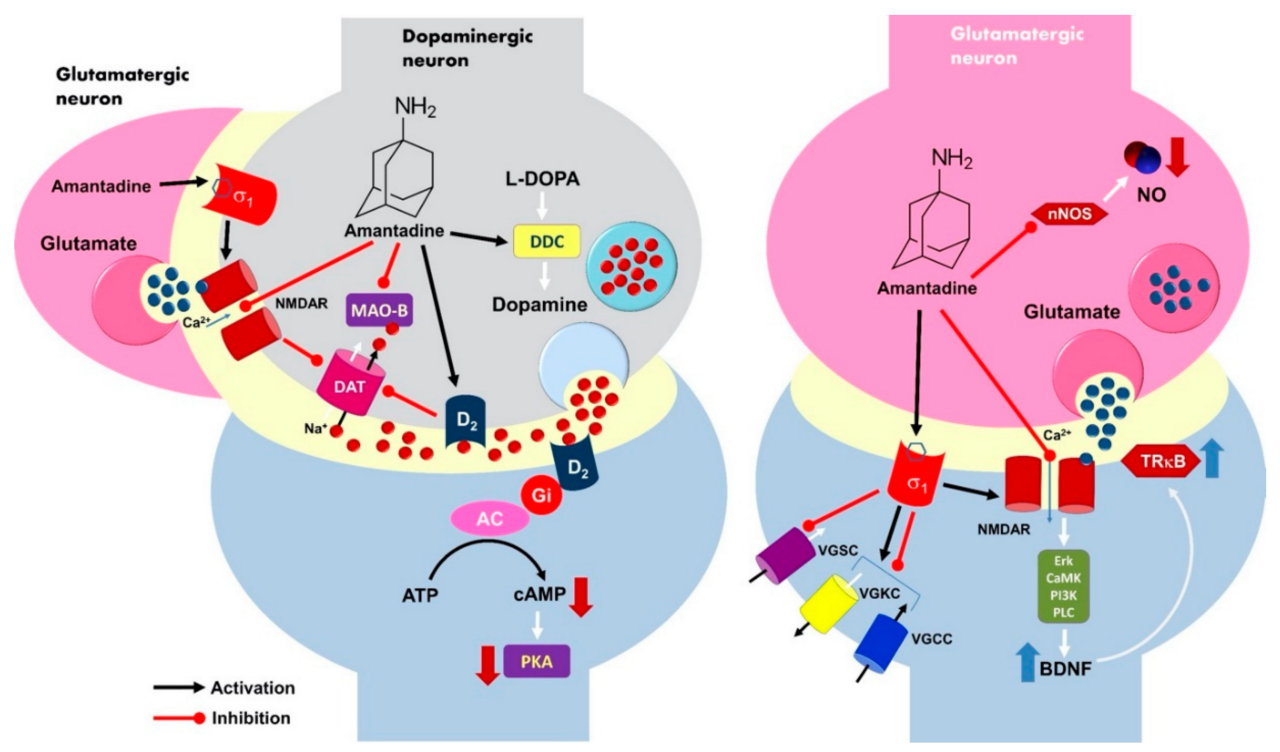

Figure 1. A model of the possible molecular mechanism of amantadine's antidepressant effects at the level of dopaminergic and glutamatergic transmission. Amantadine indirectly increases the dopamine level within the synaptic cleft due to inhibition of the dopamine transporter DAT1 via the blockage of the presynaptic NMDA receptor ion channel. The activation of the presynaptic dopamine receptor $\mathrm{D}_{2}$ may also reduce DAT1 activity in response to the high neurotransmitter level and/or drug binding. $\mathrm{D}_{2}$ is a Gi-coupled receptor, and its excitation causes an inhibition of the adenylyl cyclase (AC) activity, decreased cAMP production, and finally, the silencing of the protein kinase A (PKA)-dependent neuronal signaling pathway. Activation of the $\sigma 1$ receptor can additionally enhance the synaptic dopamine concentration. The $\sigma 1$ receptor regulates the activity of several voltage-gated sodium, potassium, and calcium channels, G-protein coupled receptors (GPCRs), and some protein kinases. Receptor activation causes a blockade of $\mathrm{Na}^{+}$channels (VGSC), while its interaction with $\mathrm{K}^{+}$(VGKC) and $\mathrm{Ca}^{2+}$ (VGCC) channels may be excitatory or inhibitory. The activation of the $\sigma 1$ receptor results in the enhancement of both NMDA and dopamine D1 receptors. Amantadine is able to inhibit monoaminoxidase B (MAO-B), but it does support L-DOPA decarboxylase (DCC) activity in the presynaptic neuron. The amantadine-related blockade of NMDA receptor function in the glutamatergic neurons causes an upregulation of BDNF and TrkB expression via Erk, CamK, PI3K, and PLC signalling cascade. Amantadine may also inhibit nitric oxide synthase (nNOS) activity and decrease neuronal NO level. All those neurochemical events are considered to be responsible for the generation of the antidepressant effects of amantadine. L-DOPA decarboxylase (DCC); NMDA receptor (NMDAR); phospholipase C (PLC); tyrosine receptor kinase B (TrkB); extracellular signal-regulated kinases (Erk); brain derived neurotrophic factor (BDNF); phosphoinositide 3-kinase (PI3K); calcium/calmodulin-dependent protein kinase (CamK). Up and down thick arrows indicate direction of changes, thin arrows show the course of biochemical reactions, lines with dots indicate functional connections.

Table 1. Reduction in the severity of depressive symptoms over three consecutive weeks of amantadine treatment. The table shows the doses of amantadine used in the following weeks and the improvement in depressive symptoms as a percentage reduction in relation to the baseline severity of symptoms.

\begin{tabular}{cccc}
\hline Patients & 1-st Week & 2-nd Week & 3-rd Week \\
\hline case & \multicolumn{2}{c}{ daily dose (improvement from baseline) } \\
\hline 1 (male) & $100 \mathrm{mg}(6 \%)$ & $200 \mathrm{mg}(50 \%)$ & $200 \mathrm{mg}(87.5 \%)$ \\
\hline 2 (male) & $100 \mathrm{mg}(0 \%)$ & $200 \mathrm{mg}(44 \%)$ & $200 \mathrm{mg}(75 \%)$ \\
\hline 3 (male) & $100 \mathrm{mg}(14 \%)$ & $200 \mathrm{mg}(57 \%)$ & $200 \mathrm{mg}(64 \%)$ \\
\hline 4 (female) & $100 \mathrm{mg}(66 \%)$ & $100 \mathrm{mg}(66 \%)$ & $100 \mathrm{mg}(93 \%)$ \\
\hline
\end{tabular}


The add-on treatment with amanatidine was well-tolerated, and no side effects were observed in any of the patients after adding amantadine. Treatment with amantadine was continued in each patient for 2 weeks after the symptoms improved, and then the drug was discontinued. No manic switch was observed during amantadine treatment, and no recurrence of depressive symptoms after drug discontinuation was observed.

Individual case reports are summarized below:

1. A 51-year-old Caucasian male diagnosed with bipolar disorder since 2002, when he had his first episode of mania. Since then, the patient was treated with valproic acid in the dose of $1500 \mathrm{mg}$ and lithium carbonate in the dose of $750 \mathrm{mg}$ daily (serum concentration of $0.6 \mathrm{mmol} / \mathrm{L}$ ). In 2016, he had a moderate episode of depression (16 points on HDRS). The clinical picture was dominated by anhedonia, apathy, lack of energy and motivation, anxiety, and indifference. Further attempts were made to treat depression with quetiapine $300 \mathrm{mg} /$ day, olanzapine $10 \mathrm{mg}$ together with fluoxetine $20 \mathrm{mg}$ daily, and antidepressants: sertraline up to $200 \mathrm{mg}$ daily and escitalopram up to $20 \mathrm{mg}$ daily. However, despite treatment, each time for at least 6 weeks, none of these interventions resulted in improvement. The patient was then offered to add amantadine to lithium carbonate and valproic acid in an initial dose of $100 \mathrm{mg}$ in the morning. After one week, the patient reported a slight improvement (15 points on the HDRS scale). With the patient's consent, the dose was increased to $200 \mathrm{mg}$ amantadine in the morning. After another week, the severity of depression in HDRS was 8 points. From the patient's report, the improvement occurred 3-4 days after increasing the dose of amantadine. After another week, HDRS was 2 points (Figure 2). The patient continued treatment with amantadine for another 2 weeks, then reduced the dose to $100 \mathrm{mg}$ in the morning and stopped the drug after three days. During the treatment, no side effects of amantadine were observed, no change in the manic phase, and no recurrence of depressive symptoms after drug discontinuation.

2. A 56-year-old Caucasian male treated for bipolar disorder since 2016, when he experienced a two-month manic episode. He then received valproic acid in a dose of $1500 \mathrm{mg}$ daily and olanzapine in a dose of $20 \mathrm{mg}$ in the evening. His mania symptoms resolved and he was then treated only with valproic acid. In 2017, he reported significant depression (19 points on the HDRS scale). The clinical picture was dominated by tearfulness, sadness, lack of motivation, anhedonia, lack of energy, and difficulty with concentration. He received lamotrigine at the target dose of $150 \mathrm{mg} /$ day, but after 4 months the depression was still there (15 points on the HDRS scale). He then received mirtazapine in a dose of $30 \mathrm{mg}$ in the evening, but after another 2 months, the symptoms remained (16 points on the HDRS scale). The patient was then offered to add amantadine at an initial dose of $100 \mathrm{mg}$ in the morning to valproic acid and lamotrigine. As there was no improvement after one week, the amantadine dose was increased to $200 \mathrm{mg}$ in the morning. After another week, the patient felt better (HDRS 9 points). At the visit after 3 weeks of treatment with amantadine, the patient had an HDRS score of 4 (Figure 2). He continued treatment for another 2 weeks, then lowered the dose to $100 \mathrm{mg}$ in the morning, and stopped taking the drug after 3 days. There were no adverse effects of amantadine and no change from the depressive phase to the manic one, and no relapse of depression after discontinuation of amantadine.

3. A 50-year-old Caucasian man has had bipolar disorder since the age of 31. He started psychiatric treatment in 2013, when the manic episode was followed by an episode of depression that lasted 5 months (12 points on the HDRS scale at the first visit). The patient then received quetiapine, but was unable to function professionally due to sedation at a dose of $100 \mathrm{mg}$. The treatment was changed to lithium carbonate at a dose of $500 \mathrm{mg}$ per day (serum concentration of $0.6 \mathrm{mmol} / \mathrm{L}$ ). The patient felt better ( 6 points on the HDRS scale), but in 2014 there was another episode of depression (14 points on the HDRS scale). The patient then did not respond to $20 \mathrm{mg}$ escitalopram for 6 weeks and then to $150 \mathrm{mg}$ bupropion in the morning for 2 months. He was then offered to add amantadine to the lithium carbonate in an initial dose of $100 \mathrm{mg}$ in the morning. The patient reported a slight improvement at the visit after one week of treatment (12 points on the HDRS 
scale). Due to incomplete improvement, the dose was increased to $200 \mathrm{mg}$ amantadine in the morning. According to the patient, the improvement was achieved within 2 days (6 points on the HDRS scale after 2 weeks of treatment). After 3 weeks, the HDRS was 5 points (Figure 2). After another 2 weeks, the patient stopped taking amantadine within 3 days. There were no adverse effects of amantadine, no manic switch, and no recurrence of depression after discontinuation of amantadine.

4. A 45-year-old Caucasian woman was diagnosed with BD-I in 2015. She had previously had a four-month manic episode, followed by a depressive episode for three months. She then received quetiapine at a target dose of $300 \mathrm{mg}$ in the evening. The patient tolerated the drug well, but her mood improved only after 6 months of treatment. In 2017, there was another episode of depression (15 points on the HDRS scale), after an earlier short episode of hypomania. She received $30 \mathrm{mg}$ of mirtazapine in the evening, but after 6 weeks there was no improvement and the patient gained $3 \mathrm{~kg}$ body weight. She was switched to $150 \mathrm{mg}$ bupropion in the morning, but after another 2 months, there was still no improvement. The patient was then offered to add amantadine $100 \mathrm{mg}$ in the morning to $300 \mathrm{mg}$ of quetiapine. Improvement was observed after 7 days of taking amantadine (HDRS 8 points). After 2 weeks, HDRS was 5 points, and after 3 weeks, 1 point (Figure 2). The patient took $100 \mathrm{mg}$ of amantadine for 2 weeks and then gradually, within 3 days, stopped taking it. As before, no adverse effects of amantadine, no change from the depressive phase to the manic phase, and no recurrence of depressive symptoms after discontinuation of amantadine were observed.

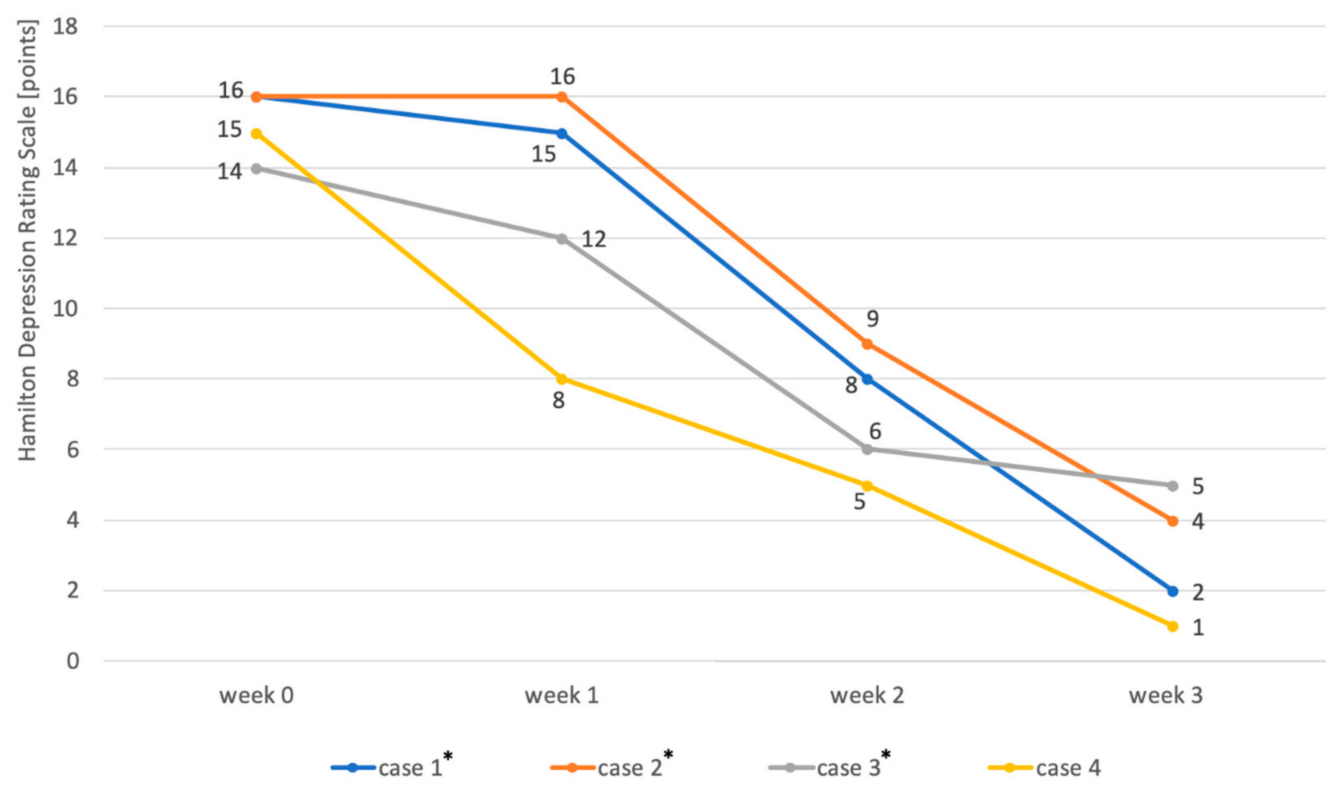

Figure 2. Changes in the severity of depression during the treatment of patients $(n=4)$ diagnosed with bipolar disorder in the depressive phase by adding amantadine to the mood stabilizer. The severity of depression was assessed using the HDRS scale four times-before the start of treatment (week 0), after the week (week 1), after 2 weeks (week 2), and after three weeks of treatment (week 3). The asterisks mark the patients whose dose of amantadine was increased to $200 \mathrm{mg} / \mathrm{day}$ in the second week. * the patients whose dose of amantadine was increased to $200 \mathrm{mg} /$ day in the second week.

\section{Discussion}

To the best of our knowledge, this is the first study showing the antidepressant effect of amantadine in BD-I. In this case series, amantadine was administered $100 \mathrm{mg}$ in the morning during the first week and was increased to $200 \mathrm{mg}$ from the second week if no clinical improvement was achieved. The adopted dose range and dose building were based on previous studies $[37,39,40]$. Gradually building up the dose of amantadine appears to be clinically more beneficial than dosing it with a high 
dose from the start. The probable cause of agitation and aggression observed in 4 people by Rizzo [38], which led to the discontinuation of the study, was the high age of people (68 years and older) and just too high of a dose regime of amantadine (300 mg/day) already at the end of the first week of treatment. Amantadine did not cause side effects in most of the previous studies, as in this study [7].

Amantadine caused a significant improvement in depressive symptoms after the first week of treatment with an effective dose in all the described patients. A similar rate of action of amantadine in patients with BDV with symptoms of bipolar depression meeting the BD-I criteria was reported by Dietrich et al. [41]. Of the 6 patients then treated with BDV infection at a dose of 100-300 mg/day, improvement occurred on average after 2.7 weeks of treatment, although in one case improvement occurred after one week and in two patients after 1.5 weeks. Due to the comorbidity of BDV, these results cannot be fully compared to the cases presented by us.

In the largest clinical trial of additive treatment with amantadine for depression in the course of treatment-resistant unipolar depression, 25 people were treated with amantadine at a dose of $150 \mathrm{mg} /$ day, which was added to imipramine at a dose of $100 \mathrm{mg} /$ day [39]. However, the severity of depression symptoms was assessed only after 3 weeks of treatment. So, it is not known what the effects of using amantadine after 1 and 2 weeks were, although the improvement after 3 weeks was modest, at $11.8 \%$ in women and $14.2 \%$ in men. In turn, in a study by Stryer et al. [40] in 7 patients with treatment-resistant unipolar depression, the improvement in the severity of depressive symptoms was fast-after 1 week it was as much as 73\%. The results of both studies concern the treatment of unipolar depression, in addition to being drug-resistant, and thus may differ from the treatment of bipolar depression. Interestingly, in a study by Stryer et al., the symptomatic improvement was greater and faster in women. Similarly, in the presented case, women suffering from bipolar depression showed improvement faster and after using a lower dose of amantadine.

Of the other drugs used to treat bipolar depression, quetiapine may also cause a rapid onset of its antidepressant effect. It has been shown that compared to a placebo, it begins to be more effective after a week of treatment [5]. This effect is probably related to the increase in BDNF levels in the hippocampus, which is the common mechanism of action of amantadine and quetiapine.

Also, intravenous ketamine given to patients with acute bipolar depression causes a rapid but transient antidepressant effect [42]. The antidepressant effect of ketamine was observed already $2 \mathrm{~h}$ after drug administration. The presumably clinical effect of amantadine in depression at doses used in patients is mainly related to its action on NMDA receptors [7]. Since both ketamine and amantadine block NMDA receptors, it can be speculated that it is the blocking of NMDA receptor function, in addition to increasing BDNF concentration, that is associated with the rapid effects of amantadine in bipolar depression.

The treatment of depressive patients with amantadine, despite its clinical efficacy confirmed in studies, is an off-label use, in the sense of repurposing of the drug. The off-label use of drugs is common in psychiatry; in the group of antidepressants alone, off-label indications have been reported in up to $29 \%$ of prescribed drugs [43]. Off-label prescribing regulations differ from country to country [44].

The presented case series shows that amantadine is not only effective in the treatment of bipolar depression but also is well-tolerated by patients. Treatment with amantadine for a short, two-week period of stabilizing improvement did not result in cycle acceleration, and discontinuation of the drug after such a period did not cause the recurrence of depressive symptoms. The reason for the short period of stabilization treatment with amantadine was to minimize the risk of manic switch reported in the Letter to the Editor by Sondré et al. [45], in which amantadine was administered to 3 patients with BD-I. Although in the cases described in this report, patients received a high dose of $400 \mathrm{mg} / \mathrm{day}$ for 8 weeks, we thought that caution should be exercised in the duration of amantadine treatment after the improvement of depressive symptoms. Our observation is limited by the size of the study group, but it may indicate that in the case of amantadine treatment it is not necessary to use a long period of stabilization of the therapeutic effect. Based on the presented series of cases, a scheme of its use in acute bipolar disorder can be proposed, presented in Figure 3. 


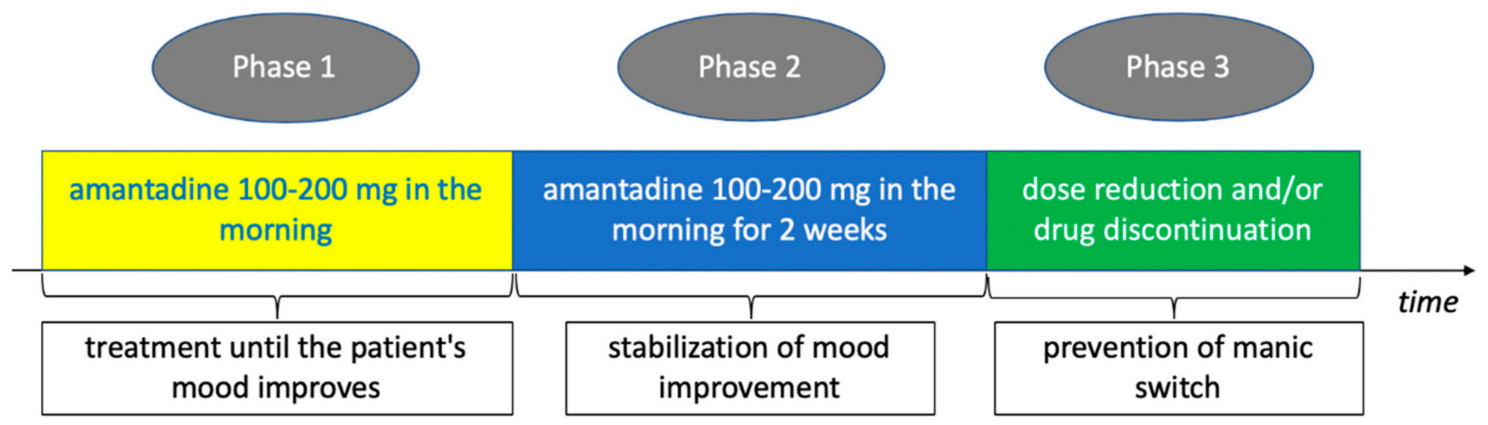

Figure 3. The proposed treatment of bipolar depression with amantadine. The duration of the first phase of treatment (Phase 1) depends on the time when a significant (50\%) improvement in the severity of depressive symptoms occurs. Limiting the duration of use of amantadine in the second treatment period (Phase 2 and 3 ) is due to the minimization of the risk of a manic switch.

The antidepressant efficacy and the observed rapid therapeutic effect of amantadine in a naturalistic open-label study are not yet evidence of amantadine's efficacy in bipolar disorder, but the results are encouraging and may be the basis for double-blind clinical trials. Confirmation of the efficacy of amantadine in acute bipolar disorder may lead to a new therapeutic indication for amantadine.

\section{Materials and Methods}

The study was an open case series study of outpatients diagnosed with bipolar disorder type I, according to the diagnostic criteria for ICD-10. When the treatment of depression was unsuccessful with at least two drugs used in the treatment of bipolar depression, patients received amanatdine at a dose of 100-200 mg daily. Amantadine was administered only in the depressive phase of at least moderate intensity. The severity of depression was assessed using the Hamilton Depression Rating Scale (HDRS) before taking the first dose of amantadine and then weekly for 3 weeks. Before receiving amantadine, each time the patient was presented with other options of pharmacological treatment and the possibility of inpatient electroconvulsive therapy. None of the patients consented to electroconvulsive treatment. All study patients were receiving at least one mood stabilizer at the time of taking amantadine. In each case, after the end of treatment with amantadine, there was at least a three months' follow-up for recurrence of depression.

According to legal regulations in Poland, all patients were informed about the mechanism of action of amantadine, its potential side effects, and the off-label use of the drug before starting amantadine. All patients consented to add-on treatment with amantadine.

\section{Conclusions}

Amantadine may be a further therapeutic option for add-on treatment of acute bipolar depression. The drug in this indication may act quickly and be well tolerated. The confirmation of the antidepressant efficacy of amantadine in bipolar depression requires replication of the obtained results and conducting clinical trials.

Author Contributions: M.K. and A.P. have made substantial contributions to the conception, design of the work and interpretation of data and has approved the submitted version. M.K. and A.P. agree to be personally accountable for the author's own contributions and for ensuring that questions related to the accuracy or integrity of any part of the work, even ones in which the author was not personally involved, are appropriately investigated, resolved, and documented in the literature. All authors have read and agreed to the published version of the manuscript.

Funding: This research received no external funding. The cost of the publication was covered by the Science for Life Foundation.

Conflicts of Interest: The authors declare no conflict of interest. 


\section{References}

1. McIntyre, R.S.; Calabrese, J.R. Bipolar depression: The clinical characteristics and unmet needs of a complex disorder. Curr. Med. Res. Opin. 2019, 35, 1993-2005. [CrossRef] [PubMed]

2. Leahy, R.L. Bipolar disorder: Causes, contexts, and treatments. J. Clin. Psychol. 2007, 63, 417-424. [CrossRef] [PubMed]

3. Kraepelin, E. Manic Depressive Insanity and Paranoia; Livingstone: Edinburgh, UK, 1921.

4. Tondo, L.; Vázquez, G.H.; Baldessarini, R.J. Depression and Mania in Bipolar Disorder. Curr. Neuropharmacol. 2017, 15, 353-358. [CrossRef] [PubMed]

5. Post, R.M. Treatment of Bipolar Depression: Evolving Recommendations. Psychiatr. Clin. North Am. 2016, 39, 11-33. [CrossRef] [PubMed]

6. Szmulewicz, A.G.; Angriman, F.; Samamé, C.; Ferraris, A.; Vigo, D.; Strejilevich, S.A. Dopaminergic agents in the treatment of bipolar depression: A systematic review and meta-analysis. Acta Psychiatrica Scandinavica 2017, 135, 527-538. [CrossRef]

7. Raupp-Barcaro, I.F.; Vital, M.A.; Galduróz, J.C.; Andreatini, R. Potential antidepressant effect of amantadine: A review of preclinical studies and clinical trials. Braz. J. Psychiatry 2018, 40, 449-458. [CrossRef]

8. Mizoguchi, K.; Yokoo, H.; Yoshida, M.; Tanaka, T.; Tanaka, M. Amantadine increases the extracellular dopamine levels in the striatum by re-uptake inhibition and by N-methyl-D-aspartate antagonism. Brain Res. 1994, 662, 255-258. [CrossRef]

9. Blanpied, T.A.; Clarke, R.J.; Johnson, J.W. Amantadine inhibits NMDA receptors by accelerating channel closure during channel block. J. Neurosci. 2005, 25, 3312-3322. [CrossRef]

10. Hosenbocus, S.; Chahal, R. Amantadine: A review of use in child and adolescent psychiatry. J. Can. Acad. Child Adolesc. Psychiatry 2013, 22, 55-60.

11. Huber, T.J.; Dietrich, D.E.; Emrich, H.M. Possible use of amantadine in depression. Pharmacopsychiatry 1999, 32, 47-55. [CrossRef]

12. Rogóż, Z.; Dlaboga, D.; Dziedzicka-Wasylewska, M.J. Effect of combined treatment with imipramine and amantadine on the central dopamine D2 and D3 receptors in rats. Physiol. Pharmacol. 2003, 54, 257-270.

13. Fisher, A.; Starr, M.S. Opposite effects of glutamate antagonists and antiparkinsonian drugs on the activities of DOPA decarboxylase and 5-HTP decarboxylase in the rat brain. Brain Res. 2000, 868, 268-274. [CrossRef]

14. Porter, R.H.; Greenamyre, J.T. Regional variations in the pharmacology of NMDA receptor channel blockers: Implications for therapeutic potential. J. Neurochem. 1995, 64, 614-623. [CrossRef] [PubMed]

15. Tan, L.; Ge, H.; Tang, J.; Fu, C.; Duanmu, W.; Chen, Y.; Hu, R.; Sui, J.; Liu, X.; Feng, H. Amantadine preserves dopamine level and attenuates depression-like behawior induced by traumatic brain injury in rats. Behav. Brain Res. 2015, 279, 274-282. [CrossRef] [PubMed]

16. Nikolaus, S.; Wittsack, H.J.; Beu, M.; Antke, C.; Hautzel, H.; Wickrath, F.; Müller-Lutz, A.; de Souza Silva, M.A.; Huston, J.P.; Antoch, G.; et al. Amantadine enhances nigrostriatal and mesolimbic dopamine function in the rat brain in relation to motor and exploratory activity. Pharmacol. Biochem. Behav. 2019, 179, 156-170. [CrossRef] [PubMed]

17. Deutschenbaur, L.; Beck, J.; Kiyhankhadiv, A.; Mühlhauser, M.; Borgwardt, S.; Walter, M.; Hasler, G.; Sollberger, D.; Lang, U.E. Role of calcium, glutamate and NMDA in major depression and therapeutic application. Prog. Neuropsychopharmacol. Biol. Psychiatry 2016, 64, 325-333. [CrossRef] [PubMed]

18. Newport, D.J.; Carpenter, L.L.; McDonald, W.M.; Potash, J.B.; Tohen, M.; Nemeroff, C.B. APA Council of Research Task Force on Novel Biomarkers and Treatments Ketamine and other NMDA antagonists: Early clinical trials and possible mechanisms in depression. Am. J. Psychiatry 2015, 172, 950-966.

19. Mathew, S.J.; Keegan, K.; Smith, L. Glutamate modulators as novel interventions for mood disorders. Revista Brasiliera Psiquiatria 2005, 27, 243-248. [CrossRef]

20. Page, G.; Peeters, M.; Maloteaux, J.M.; Hermans, E. Increased dopamine uptake in striatal synaptosomes after treatment of rats with amantadine. Eur. J. Pharmacol. 2000, 403, 75-80. [CrossRef]

21. Dutta, A.; McKie, S.; Deakin, J.F. Ketamine and other potential glutamate antidepressants. Psychiatry Res. 2015, 225, 1-13. [CrossRef]

22. Moryl, E.; Danysz, W.; Quack, G. Potential antidepressive properties of amantadine, memantine and bifemelane. Pharmacol. Toxicol. 1993, 72, 394-397. [CrossRef] [PubMed] 
23. Rogóż, Z.; Skuza, G. Effect of repeated co-treatment with fluoxetine and amantadine on the behavioral reactivity of the central dopamine and serotonin system in rats. Pharmacol. Rep. 2009, 61, 924-929. [CrossRef]

24. Peeters, M.; Romieu, P.; Maurice, T.; Su, T.P.; Maloteaux, J.M.; Hermans, E. Involvement of the sigma 1 receptor in the modulation of dopaminergic transmission by amantadine. Eur. J. Neurosci. 2004, 19, 2212-2220. [CrossRef] [PubMed]

25. Kornhuber, J.; Schoppmeyer, K.; Riederer, P. Affinity of 1-aminoadamantanes for the sigma binding site in post-mortem human frontal cortex. Neurosci. Lett. 1993, 163, 129-131. [CrossRef]

26. Nuwayhid, S.J.; Werling, L.L. Sigma1 receptor agonist-mediated regulation of $\mathrm{N}$-methyl-D-aspartate-stimulated [3H]dopamine release is dependent upon protein kinase C. J. Pharmacol. Exp. Ther. 2003, 304, 364-369. [CrossRef]

27. Wang, J.; Mack, A.L.; Coop, A.; Matsumoto, R.R. Novel sigma (sigma) receptor agonists produce antidepressant-like effects in mice. Eur. Neuropsychopharmacol. 2007, 17, 708-716. [CrossRef]

28. Narita, N.; Hashimoto, K.; Tomitaka, S.; Minabe, Y. Interactions of selective serotonin reuptake inhibitors with subtypes of sigma receptors in rat brain. Eur. J. Pharmacol. 1996, 307, 117-119. [CrossRef]

29. Itzhak, Y.; Kassim, C.O. Clorgyline displays high affinity for $\sigma$-binding sites in C57BL/6 mouse brain. Eur. J. Pharmacol. 1990, 176, 107-108. [CrossRef]

30. Castren, E.; Kojima, M. Brain-derived neurotrophic factor in mood disorders and antidepressant treatments. Neurobiol. Dis. 2017, 97, 119-126. [CrossRef] [PubMed]

31. Rogóż, Z.; Skuza, G.; Legutko, B. Repeated co-treatment with fluoxetine and amantadine induces brain-derived neurotrophic factor gene expression in rats. Pharmacol. Rep. 2008, 60, 817-826. [PubMed]

32. Rogóż, Z.; Skuza, G.; Legutko, B.J. Repeated co-treatment with imipramine and amantadine induces hippocampal brain-derived neurotrophic factor gene expression in rats. Physiol. Pharmacol. 2007, 58, $219-234$.

33. Amidfar, M.; Kim, Y.K.; Wiborg, O. Effectiveness of memantine on depression-like behavior, memory deficits and brain mRNA levels of BDNF and TrkB in rats subjected to repeated unpredictable stress. Pharmacol. Rep. 2018, 70, 600-606. [CrossRef]

34. Walia, V.; Garg, C.; Garg, M. Amantadine exerts anxiolytic like effect in mice: Evidences for the involvement of nitrergic and GABAergic signaling pathways. Behav. Brain Res. 2020, 380, 112432. [CrossRef] [PubMed]

35. Berk, M.; Dodd, S.; Kauer-Sant'anna, M.; Malhi, G.S.; Bourin, M.; Kapczinski, F.; Norman, T. Dopamine dysregulation syndrome: Implications for a dopamine hypothesis of bipolar disorder. Acta Psychiatrica Scandinavica Suppl. 2007, 434, 41-49. [CrossRef] [PubMed]

36. Van Rossum, I.; Tenback, D.; van Os, J. Bipolar disorder and dopamine dysfunction: An indirect approach focusing on tardive movement syndromes in a naturalistic setting. BMC Psychiatry 2009, 9, 16. [CrossRef] [PubMed]

37. Vale, S.; Espejel, M.A.; Dominguez, J.C. Amantadine in depression. Lancet 1971, 2, 437. [CrossRef]

38. Rizzo, M.; Biandrate, G.; Tognoni, G.; Morselli, P.L. Amantadine in depression: Relationship between behavioral effects and plasma levels. Eur. J. Clin. Pharmacol. 1973, 5, 226-228. [CrossRef]

39. Rogóz, Z.; Skuza, G.; Daniel, W.A.; Wójcikowski, J.; Dudek, D.; Wróbel, A. Amantadine as an additive treatment in patients suffering from drug-resistant unipolar depression. Pharmacol. Rep. 2007, 59, 778-784.

40. Stryjer, R.; Strous, R.D.; Shaked, G.; Bar, F.; Feldman, B.; Kotler, M.; Polak, L.; Rosenzcwaig, S.; Weizman, A. Amantadine as augmentation therapy in the management of treatment-resistant depression. Int. Clin. Psychopharmacol. 2003, 18, 93-96. [CrossRef]

41. Dietrich, D.E.; Bode, L.; Spannhuth, C.W.; Lau, T.; Huber, T.J.; Brodhun, B.; Ludwig, H.; Emrich, H.M. Amantadine in depressive patients with Borna disease virus (BDV) infection: An open trial. Bipolar Disord. 2000, 2, 65-70. [CrossRef]

42. Zarate, C.A.; Singh, J.B.; Carlson, P.J.; Brutsche, N.E.; Ameli, R.; Luckenbaugh, D.A.; Charney, D.A.; Manji, H.K. A Randomized Trial of an N-methyl-D-aspartate Antagonist in Treatment-Resistant Major Depression. Arch. Gen. Psychiatry 2006, 63, 856-864. [CrossRef] [PubMed]

43. Wong, J.; Motulsky, A.; Eguale, T.; Buckeridge, D.L.; Abrahamowicz, M.; Tamblyn, R. Treatment indications for antidepressants prescribed in primary care in Quebec, Canada, 2006-2015. JAMA 2016, 315, 2230-2232. [CrossRef] [PubMed] 
44. Skånland, S.S.; Cieślar-Pobuda, A. Off-label uses of drugs for depression. Eur. J. Pharmacol. 2019, 865, 172732. [CrossRef] [PubMed]

45. Sodré, L.A.; Bücker, J.; Zortéa, K.; Sulzbach-Vianna, M.F.; Gama, C.S. Mania switch induced by amantadine in bipolar disorder: Report of three cases. Braz. J. Psychiatry 2010, 32, 467-469. [CrossRef] [PubMed]

Publisher's Note: MDPI stays neutral with regard to jurisdictional claims in published maps and institutional affiliations.

(C) 2020 by the authors. Licensee MDPI, Basel, Switzerland. This article is an open access article distributed under the terms and conditions of the Creative Commons Attribution (CC BY) license (http://creativecommons.org/licenses/by/4.0/). 